\title{
The Anatomy of a Human Body, a Model to Design Smart High Building
}

\author{
Katayoun Taghizadeh*, Matin Bastanfard \\ Department of Architecture, University of Tehran, Tehran, 1417466191, Iran
}

\begin{abstract}
Today, population growth and the rise in real estate price have made the growth and development of cities in a vertical manner inevitable. The benefits of developing a city vertically include land preservation, the reduction of environmental damage, traffic and transportation as well as reducing environmental pollution and energy consumption caused by horizontal expansion. Designing a high building is a complex process, particularly in regards to its structure. Since the beginning of civilization, the nature with its secrets has been a valuable tool for solving such problems. Bionic is a science that can eradicate this gap between nature and technology. Bionic is the science that is formed from the combination of various natural and engineering science concepts. It is the study of complex vital systems of live organisms and natural forms and maybe a good solution for solving technical and structural issues of engineers. The structure of human body has been considered as a good example of a tall structure with a reasonable ratio of the height to the base. This model may serve for designing high buildings with particular attention to three aspects. First human body structure: in this section the body's skeleton, the spinal cords curves, its connections, and the routes of energy transmission are analyzed. Second the human's brain, intelligent controller of the body. The human brain has two major functions; reaction to stimuli and commanding other organs. The distribution and connection of nerves in the brain and throughout the body are discussed in this section. Third human skin, a model for the rind of high buildings: skin with its complex ability has a significant role in converting human body to a micro climate. Self-repairing, energy absorption, and thermal insulation are among other features are discussed in this section. At the first step, the method of research in this study is based on the study of human's anatomy and similar subjects, and the discussion with medical and experimental sciences experts. We will discuss and analyze each topic separately in details. The goal of this research is to start a path toward providing a model for designing intelligent high buildings with the use of the human body as a model.This document gives formatting instructions for authors preparing papers for publication in SAP. The authors must follow the instructions given in the document for the papers to be published. You can use this document as both an instruction set and as a template into which you can type your own text. The body of abstract immediately follows abstract heading in the same paragraph. For example, this paragraph begins with abstract heading
\end{abstract}

Keywords Tall Building, Bionics, Human Body, Structure, Skin, Intelligent Control

\section{Introduction}

High-rise building more than any other characteristic, known as the superior technology materials and equipment specific performance, integral components of this technology are superior. Until the 19th century, buildings were limited to the highlands churches, pyramids, castles, amphitheater, mosques and churches were the epitome of strength and faith. Beginning in the 19th century, gradually replacing structural steel in building a heavy-duty construction and the invention of the elevator. Height restriction of 5 -storey building destroyed. Construction of tall buildings

* Corresponding author:

ktaghizad@ut.ac.ir (Katayoun Taghizadeh)

Published online at http://journal.sapub.org/scit

Copyright (C) 2012 Scientific \& Academic Publishing. All Rights Reserved in the world was very well received, and the opportunity to show off and compete to provide world architecture. To compete in this field over the height, but now with the help of new technology it has become easy As far as high-rise in the world today, "being better" is more important than "being higher".

The world of skyscrapers involved various sciences such as electronics, mechanics, computers, and .... and introduced new skyscraper: Dynamic Tower, green skyscrapers, towers Layzerland Tower and Finally bionics Tower.

Bionic tower, which is based on knowledge of different concepts such as combining the Natural Sciences and Engineering in the study of complex biological systems in living organisms is the result of the analysis of natural form [1]. Bionic skyscraper in this paper is a tall intelligent building regarding of the human.

Recent advances in materials, the construction techniques, calculation methods and structures, have created expanded 
considerably new freedom in architectural design and tall building design has. This new freedom, are not exempted the modern structure of the basic principles These principles include: balance, stability, strength, performance, economics, aesthetic[2] that the best principles of natural structures such as the human body is manifested.

\section{Nature Template and Architecture}

\subsection{History of Human and Nature Template}

Human history has been in constant contact with nature. This relationship in different eras, has had various forms, which are generally divided into the following four courses [3].

1. Nature and organic template (the Hunting Age or Stone Age): In this course, human being has been dominated by nature on all aspects of life.

2. Nature and Hyper organic template (the farm): In this period, the expectation level of comfort to the people of the area of security, Vance was trying to tune "with nature" or "with nature" comes on.

3. Nature and dominate nature template (the industrial revolution): in this period human expectation level was security, justice and welfare. In this period, the maximum utilization of human nature is to win.

4. Nature and industrial quasi-organic template. Although well motivated in this period still exists, but the environmental damage up and global community is trying to adapt industry to nature[4].

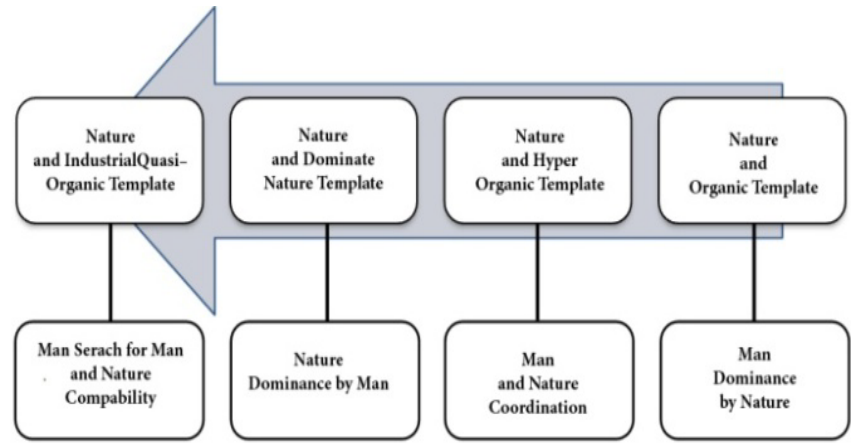

Figure 1. History of Nature Templates

\subsection{Nature as a System}

\subsubsection{Defining System}

System to set or group of related or unrelated objects are referred to as the target or the specific goals are pursued, so that they form a single complex. The Constitution defines three key words are noteworthy:

- Set or group

- Common target

- The complex unit

So system can be defined as different species. Various systems can also be classified as: Open - closed system, static system - dynamic system, natural system - artificial system, and ...

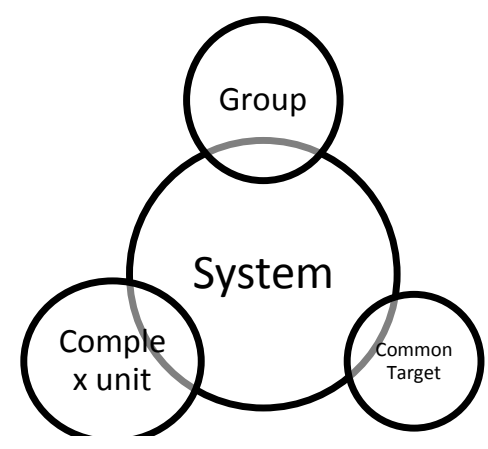

Figure 2. Components of a System

\subsubsection{System of Nature}

Each natural element has always been a system consists of several components and elements, which will boost the overall complex, the total of all goal (or goals) to meet the specific makes. Nature is a system analysis, the analysis is more accurate. In fact, we can say that the study of nature, is able to achieve this vision system, understand the power structures of rule-based analysis to understand the nature provides. Each of these natural systems are converted to a number of subsystems, in which each of these subsystems are also a number of runs, each of these components is also a separate system.

For example, if the body is considered as a whole system, this system of different species, can be divided into several subsystems. Regarding to Function, the human body is consists of respiratory system, D system, digestive system, visual system, auditory system, and .... Each of these systems in permanent interaction with the other systems and are formed of several components. For example, the human digestive system is composed of the gut and digestive glands. Digestive tube, including its subsystems, such as the mouth, throat, esophagus, stomach, small intestine, colon and rectum, which each of these components alone complex system with other systems is included.

\subsection{Different Types of Systems Modeled on Nature}

Nature is an infinite source of inspiration, which can be a good teacher in various fields of science, knowledge, technology and architectural design. The purpose of copying and imitation of nature is not detailed, but identification Process of principles governing the issue is important, that should not be neglected[5]. In general, different species can be modeled from nature found in the following cases:

- Formal or form modeled from nature: The simplest method is modeled from nature, that's enough to imitation, and not heed the logic

- Modeled a metaphor: in this way, modeled from nature to abstraction is used to balance and steady. Metaphors are open to the extent creativity in architecture, it can be considered as strategic[5].

- Breda model laws and regulations of Nature: This is the most desirable method of copying nature, which requires more study and the better the results will follow. This is the way that the same rules modeled on laws of nature. 


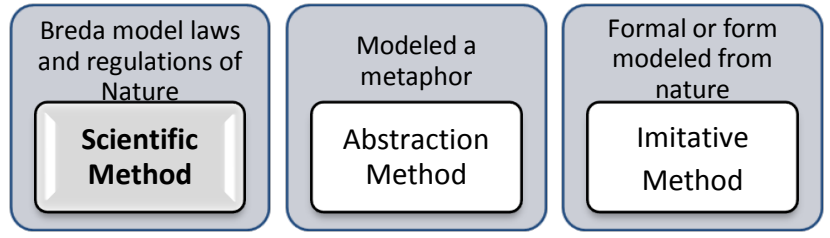

Figure 3. The Nature of the Modelled Species

\section{Bionics}

\subsection{Semantic Bionics}

Bionics in the dictionary means nature of the application of artificial organs. The term "bionics" was created in 1958 by Jack. E. Steele, a worker at the Aeronautics Division House at the Wright-Patterson Air Force Base in Dayton, Ohio. He Considered bionics and the foundation of all knowledge systems as living systems. Bionics science or study of organisms living today as one of the world's top science (IT, Nano, Bionic) has been introduced. Of a general definition can be said to "attentively bionics science foundation system that they are living systems or features live system or systems to survive[6]. Bionics is combining of two words "biology" and "techniques" means the knowledge of technical solutions to biological responses.

\subsection{Bio-Based Architecture}

Enliven the building is one of the main tendencies of this kind of architecture. Charlie Luxton one of the pioneers in the field of Bionic architecture says the main point of this architecture, is best using materials which cause the strength of building and architectural flexibility and variety. Bio-based architecture on the here considered authors, as in architectural design inspired from nature, which is focused on the rules of laws that govern nature. In fact, Bionics architecture is engineering design process based on the new systems which are available in nature.

\section{Bionics and Tall Buildings Design}

Design a building as the result of detailed studies and the process is complex, with many challenges surrounding such as structural, mechanical and electrical, cooling, shell building, protection, and security and so on. Since the beginning of human life, a world of mystery of nature has been a good instrument for solving these challenges and bionics bridging the gap between nature and technology.

Construction is usually based on a common simple system such as: column, beam, electrical and mechanical ducts. But the nature is based on sustainable development of complex systems. As mentioned, bionics is knowledge of combination of different concepts of Natural Sciences, Engineering, formed with the study of complex biological systems, living organisms, natural forms, respond well to solve the technical problems of structure engineering. Bionics structures with caused a revolution in technology development and its as- sociated structures in the world of science that is still being developed.

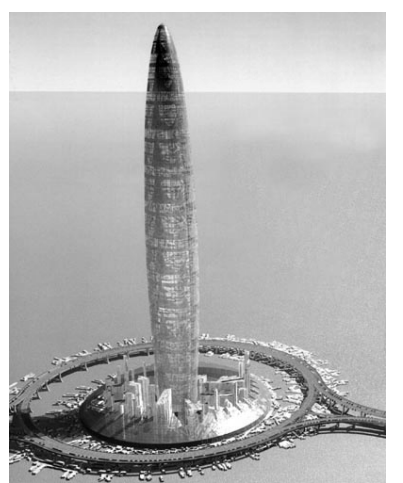

Figure 4. Shanghai Bionic Tower based on bionics model of the tree root

Bionic Tower is the natural model for use in structural design model offers a smart feature. Application of Natural templates for tall buildings structural design, focused not only natural, and so much more to be said, the building shell can both be involved so it intelligence.

\section{The Structure of the Human Body in the Design of Tall Buildings}

\subsection{The Structure of the Body as a Model for the Design of Tall Buildings}

Define a building as tall buildings, the proportion of building height or diameter that determines the type of geometry, which is high in these categories is given in Table 1. According to this definition, for a man be considered, $\mathrm{H}$, and $\mathrm{D}$ averaged 180 and $40 \mathrm{~cm}$, so $\mathrm{H} / \mathrm{D}$ value of 4.5 is obtained, the human body among the structures is long to very long.

Table 1. High Definition based on Ratio of height to cross section

\begin{tabular}{|c|c|c|c|c|}
\hline $\begin{array}{c}\text { Ratio of height to } \\
\text { cross section H/D }\end{array}$ & $1.5 \pi$ & $\pi$ & $0.5 \pi$ & $1 / 3 \pi$ \\
\hline Building Type & Very Tall & Tall & Average & Short \\
\hline
\end{tabular}

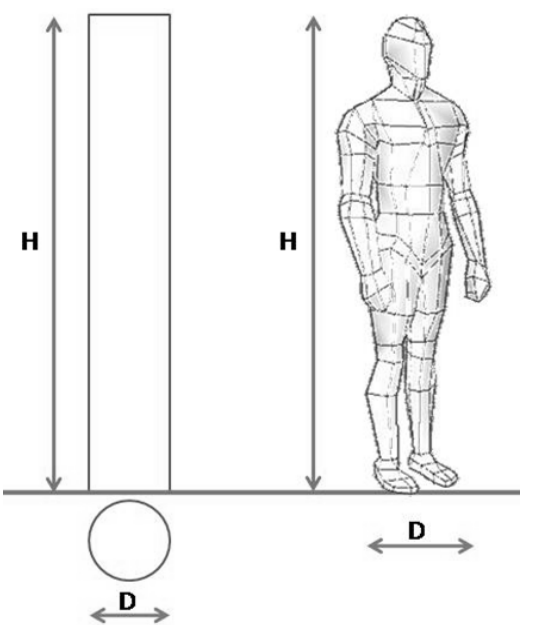

Figure 5. Height ratio of the cross section scale for high levels

\subsection{Human Skeleton, a Structure of Accountability with Different Structure}




\subsubsection{Structure of Human Body}

Bones are Structural components of the human body and as the load bearing elements are classified into three categories, including: at the top skull bones, spine as intermediate structures and the leg bone as the transmission to earth.

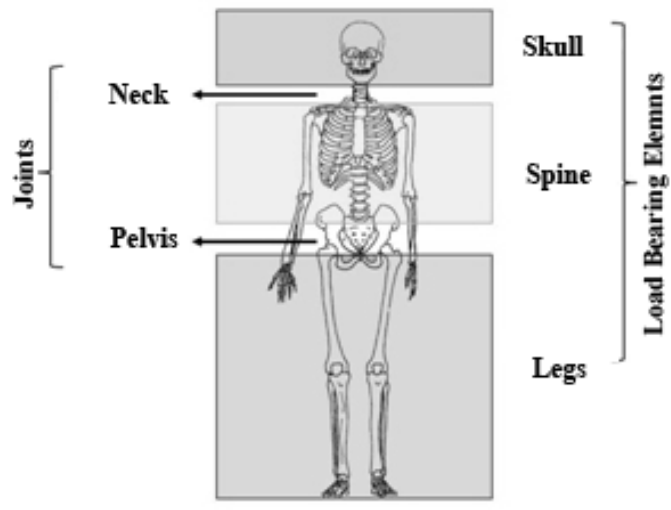

Figure 6. Human body load-bearing elements and joints

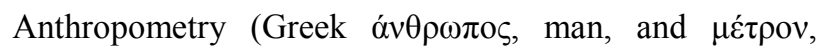
measure, literally meaning measurement of humans), in physical anthropology, refers to the measurement of the human individual for the purposes of understanding human physical variation.[7]

Significant issue in the general form of the human skeleton, location of neutral axe face angle is the Firmware of this structure. Perfect symmetry in the angle of the human body is established, the forces transferred to the hip bone, and by two legs into the ground. By this way the neutral axe position, is on the axis of symmetry, according to the spine. But in the middle of the structure's natural angle, the forward torque breast created moment, which will move the neutral axis. Toes strain in this structure, it is so accurate which creates a reverse moment, the best way to make the desired balance.

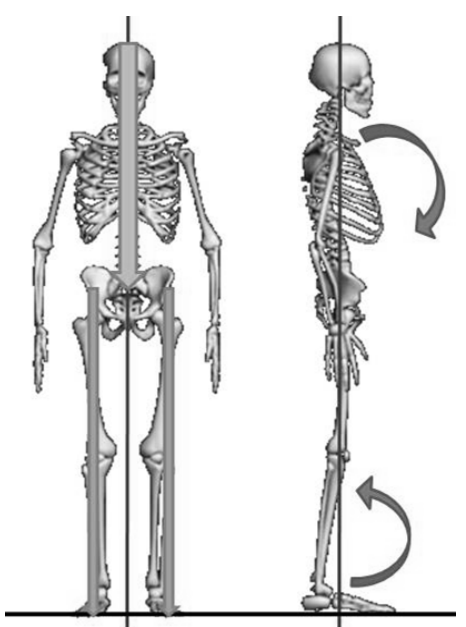

Figure 7. Neutral Axe position and balance by inverted moment

\subsubsection{Tension, Compression and Torsion Forces Strength}

Human body in both tensile and compressive forces strength. Pressure of the bones and muscles are responsible for all human beings, with elastic, in force (for example, when lifting an object) to the tension in the muscle under maximum stress in this case. Unique strong point of this structure, the compressive and tensile elements together is taking place.

Tensile strength of the elements are not (unlike the bars inside the concrete), but together with the binding complex, have created a single system. Withstand the tensile forces, are not confined to the muscles and bones, with its complex structure, and are responsible for the task.

Bones, such as a reinforced concrete steel bars such as collagen, which seems to have taken place in the body. Collagen is the protein fibers that are strong in bone, tendons, and ligaments. If the amount of bone collagen, and calcium absorption reduces, bone is not enough, stability against pressure decreases (calcium as a constituent of concrete aggregate). Collagen is also used in tendon structure. Leg's tendons in the joints act as a warning and a safety valve.

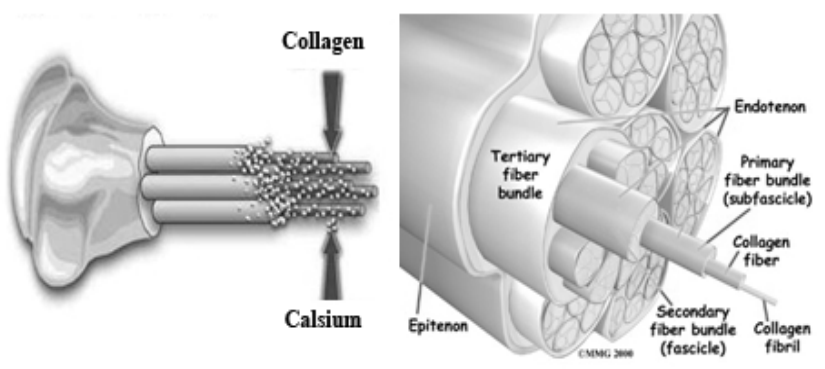

Figure 8. Collagen fibers in the tendons of pipes and intra-specific categories

In ligaments and tendons, collagen fibers with regular arrangement of the rows have been together long, the arrangement to handle a switch to wood that would make more difficult to break them. It can be said in a preliminary simulation that the reinforcing bars, and even mesh networks act in a way similar to collagen within tendons, in fact, factors caused strengths.

Bone is an excellent example of intelligent biological materials for the microscopic structure is consistent with the surrounding environment. For example, the tibia and the spiral arms are flexible collagen fibers to the bone torsional strength required to withstand this on the bones of that and create an efficient load transfer mechanism of these bones form a cylinder, compact and light weight of a hollow structure and optimized geometry of a flat and porous in detail become.

The Wolf (1892) law as the dominant theory of classical architectural elements has been bone. This law was later amended to take on further progress and now can be expressed as follows: the bone in line with their foreign re-Placement or Placement in response to these forces may increase or reduce its mass.

\subsubsection{Structural Joints of Human Skeleton, a Model for Future Structural Connections}

From point of view of biomechanics, human body is a complex set of levers, the external forces cause the moment around the joint (support) are produced by muscles and force the system into balance. The human body as a lever system, 
will be divided into three categories:

- First class lever: Lever where the support is located between the load and force, such as lever system of the neck vertebrae Atlas.

- Second class lever: Lever where the support is located at one end and force the other end, such as lever system of the body to help lift the big toe joint, muscle twins.

- The third class lever: lever where the support is located at one end and the load at the other end, and the force that may be applied at any point between the support and load, such as the elbow while holding a weight lever system.

Structural joints are divided to rolling, hing and rigid joints. Skull is the only body part that has rigid joint. Other connections in the human body are hinged. Joints are formed at the junction of two or more bones. Different types of joints, providing varying degrees of movement. Semi-movable joints such as spine joints make stability, and are somewhat flexible. Most joints, which called synovial, can move freely. In rigid joints, due to excessive force, failure occurs at the junction, but in the articular joints, tongue and groove are out of place. Detailed hinged connection pattern, can be very good for the architectural construction. Especially in the construction of mobile and flexible structures, one of the major goals of the architecture of the future.
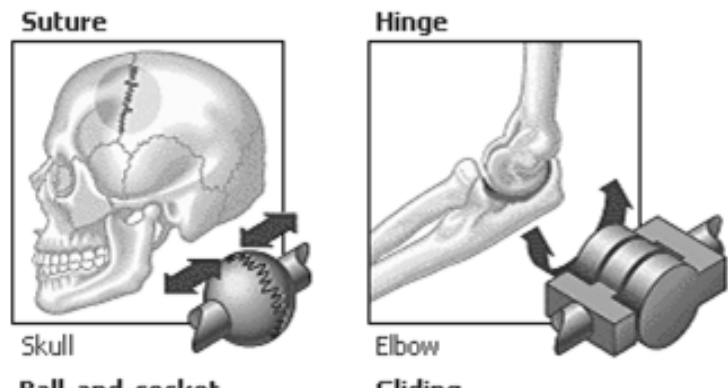

Ball-and-socket

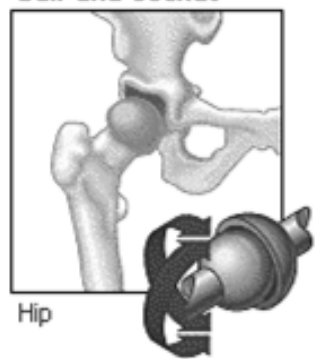

Gliding

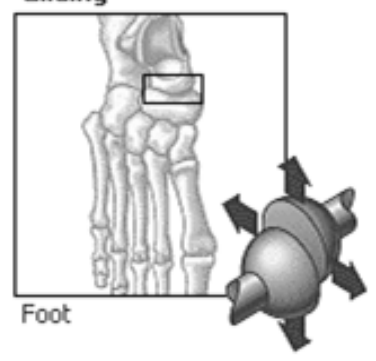

Figure 9. Types of human body connections

\subsection{Skin as a Pattern for Tall Buildings Membrane}

\subsubsection{Structure of Skin}

The skin is a vital organ without which no creature is able to survive. Skin as the largest living member of the body, in fact one of the most complex, most interesting and the body count is the most prolific members. The human body is composed of several layers of skin, including 650 secreted sweat glands, 65 hair follicles, 19 yards of fine blood capillaries, cells of touch, nerve endings and Langerhans cells per square inch of skin, which is also their cells melanin production should also be added.
A biological material like human skin, and elasticity that are soft, very resistant to fracture or rupture. The inherent tendency to re-orientation of collagen fibers and elastin in the event of deformation, the situation has not changed. Also, collagen and elastin fibers in the direction perpendicular to the crack tip are drawn to the situation of tension is smoother and safer[3].

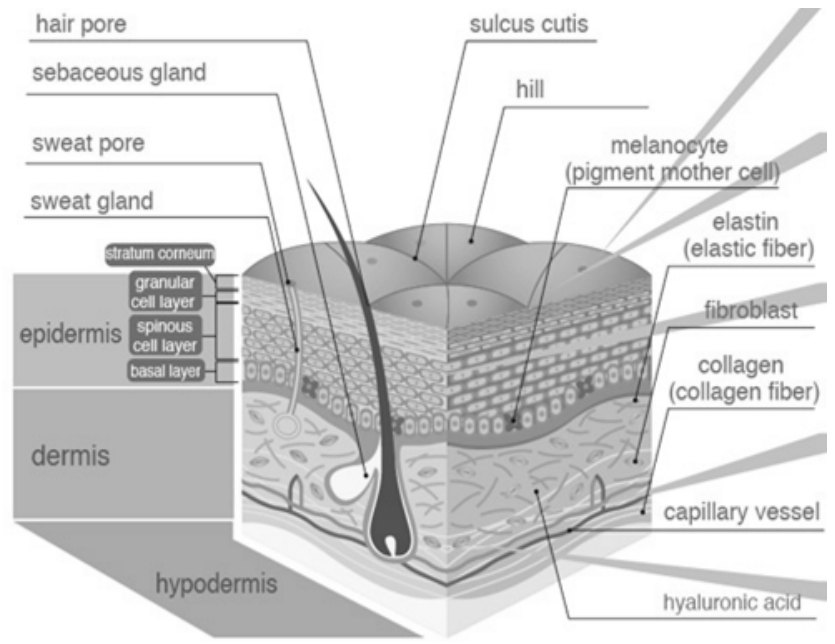

Figure 10. Structure of human body Skin

\subsubsection{Expectations for the future Design of the Tall Building} Shell, along with Human Skin

The skin protect body against mechanical damage, extreme heat, light, (mechanical defense system), and prevent from the influence of chemicals and microbes and micro-organisms entering the body (immunological defense system). Some of the harmful substances produced by metabolic activity in the liver and excreted in the digestive system, and hormones and enzymes are retained within the body. Skin as a foreign touch, sensory impulses through the nerves to the brain and nerve centers and transported to Langerhans cells, may play an important role in the immune system.

Table 2. Human body and future tall buildings comparison

\begin{tabular}{|c|c|}
\hline Tall building's skin exceptions & Human body capacities \\
\hline $\begin{array}{l}\text { Control the amount of light } \\
\text { inside building }\end{array}$ & $\begin{array}{c}\text { Mechanical defense: } \\
\text { Control the amount of sun's light and } \\
\text { heat }\end{array}$ \\
\hline $\begin{array}{c}\text { Absorbs solar energy for use } \\
\text { in mechanical systems and } \\
\text { electricity production }\end{array}$ & Absorb solar energy and vitamins \\
\hline $\begin{array}{l}\text { ability to create restorative } \\
\text { skin }\end{array}$ & ability to create restorative skin \\
\hline $\begin{array}{l}\text { change building's skin color in } \\
\text { different situations in different } \\
\text { weather conditions }\end{array}$ & $\begin{array}{c}\text { change skin color in different situa- } \\
\text { tions }\end{array}$ \\
\hline $\begin{array}{c}\text { Create a small indoorclimate } \\
\text { inside building }\end{array}$ & $\begin{array}{l}\text { Prevent water evaporation from the } \\
\text { body }\end{array}$ \\
\hline and so on & and so on \\
\hline
\end{tabular}

\subsubsection{Nanotechnology Developments, the Theme of} Intelligent Buildings

Nanotechnology will play a pivotal role in the future of 
architectural design, as this movement has started, will continue to grow. A number of materials with nano-engineered buildings is now available to architects, producers, the change buildings using these materials, discussion of architecture today. Some examples of products that are produced in those cases is included. That are resistant against scratches thin window, and automatically receive the sun's ultraviolet rays can clean themselves. Colored glass that increases or decreases with ambient temperature change (Similar reaction in the skin) and ...

Nano-materials, with a process that will follow, all will meet the demands of an intelligent man from a shell. Nanotechnology is changing the structure of human life, has created a fundamental change. If the building (or a skyscraper) with skin like a protective skin is the body with all its capabilities, will revolutionize the future of skyscrapers. "Maybe some prediction about nanotechnology seem exaggerated, but the ultimate goal of making a material with properties that we expect it" [8].

\subsection{The Human Brain, As a Smart Management Template in Tall Buildings}

\subsubsection{The Human Brain and Nervous System}

The nervous system, which has a special structure and, in order to coordinate actions between differentiated cells and organs of the body and was evolved. Nervous system from the perspective Cognitive framework are divided in two, central nervous system include the brain and spinal cord of and nervous environment of 12 pairs of nerve fibers in brain and 31 pairs of nerve cord that connect the brain and spinal cord to other parts of the body. Nervous system, the body covered, and all organs in direct contact with a controller has been strong, which is the brain. Overall performance management system to the brain as the body can react in two main categories of stimulants, and issuing commands to other components.

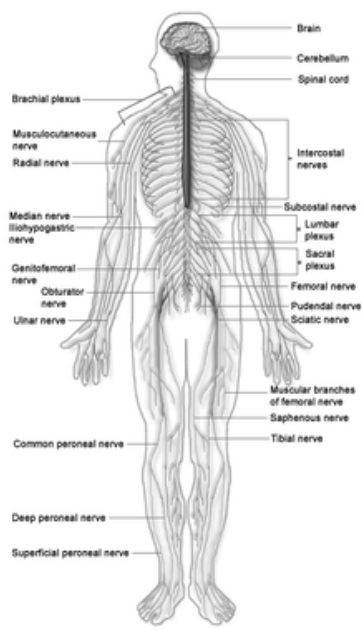

Figure 11. Brain, spinal cord and nervous system of human body

\subsubsection{The brain of Future High Rise Buildings}

The human brain is a model for a strong management system. Systems management structures coming up in the article "High-rise building's brain" was called, and the same military that is predicted for the human brain. What a smart system for a central building is expected to include:

- Response to any change in the structural connections

- Response to movement building in earthquake, wind or

- Response to changes in humidity and temperature inside the building

- Response to smoke in indoor

- Vsdmat human response to vandalism and (in case of military attack, etc.)

- Response to electrical system problems

- Response to mechanical problems (water, sewer, ...)

and human resources management, collection actions will be necessary. The intelligence of such a system, the visionary architects, structural engineers, researchers sciences, electronics, computers and ... In a joint study, consistent and targeted, will be able, in the not too distant future that covers fulfilled.

\section{Conclusions}

Architecture and engineering have traditionally treated structure as static - the building frame was constructed to be strong and heavy enough to resist all anticipated loads. Human body as a template for tall buildings design proposes a lighter, dynamic structural system that actively responds to forces placed upon it. Controlled by wind detecting sensors, stabilizing aileron-like fins run the length of the tower frame and modulate their position to control resonant motion and building drift. The separation of the structural frame and the building envelope enhances the quality of the interior space by providing an abundance of natural light and ventilation.

Approaching the tower as a theoretical project has proven liberating, freeing to seek new solutions to technical problems, to find creative approaches outside the present financial climate, and to implement environmentally sustainable strategies that will enhance the next generation of ultra-high rise buildings. Our paradigm is the human body. These near-future towers incorporates structural and climatic systems that, like the human body, respond dynamically and efficiently to forces placed upon them.

\section{REFERENCES}

[1] http://cerveraandpioz.com

[2] Salvadori, Mario George (1986), Structure in Architecture: The Building of Buildings, Prentice Hall

[3] Smith, David Lee (2001), Environmental Issues for Architecture, Wiley

[4] Hamzenazhad, Mahdi (2006), Human, Nature, Architecture, University of Science and Technology press, Teharn 
[5] Antoniades, Anthony C. (2008), Poetics of Architecture: Theory of Design, Wiley

[6] Gerardin, Lucien (1968), Bionics (World university library), McGraw-Hill

[7] Wikipedia

[8] Richardso Phyllis (2001), Nano House: Innovations for Small Dwellings, Thames \& Hudson

[9] Netter, Frank Henry and Jones H. Royden (1983), The Ciba Collection of Medical Illustrations: Nervous system. pt. 1.
Anatomy and physiology, Ciba Pharmaceutical Company Commissioned and published by Ciba

[10] Netter, Frank Henry and Jones H. Royden (1983), The Ciba Collection of Medical Illustrations: Nervous System: Neurologic and Neuromuscular Disorders, Ciba Pharmaceutical Company - Commissioned and published by Ciba

[11] Romanes, G. J (1981), Cunningham's textbook of anatomy, Twelfth edition. Oxford: Oxford University Press

[12] URL1: http://www1.iranmedical.net/Post-589.aspx 